\title{
Non-Invasive Vibration-Stress of the Cirrhotic Liver of Patients Waiting for Transplantation Induces of Circulating CD133+ Stem Lymphocytes Committed Phenotypically toward the Liver
}

\author{
Aleksei N. Shoutko1 ${ }^{*}$, Olga A. Gerasimova², Vyacheslav A. Fedorov¹, Fiodor K. Zherebtsov² \\ ${ }^{1}$ Laboratory for Improvement of the Cancer Treatment Methods, A. M. Granov Russian Research Center for Radiology and \\ Surgical Technologies, Saint-Petersburg, Russia \\ ${ }^{2}$ Transplantation Division, A. M. Granov Russian Research Center for Radiology and Surgical Technologies, Saint-Petersburg, \\ Russia \\ Email: *info@rrcrst
}

How to cite this paper: Shoutko, A.N., Gerasimova, O.A., Fedorov, V.A. and Zherebtsov, F.K. (2019) Non-Invasive Vibration-Stress of the Cirrhotic Liver of Patients Waiting for Transplantation Induces of Circulating CD133+ Stem Lymphocytes Committed Phenotypically toward the Liver. Open Journal of Biophysics, 9, 155-168. https://doi.org/10.4236/ojbiphy.2019.93012

Received: May 3, 2019

Accepted: May 27, 2019

Published: May 30, 2019

Copyright $\odot 2019$ by author(s) and Scientific Research Publishing Inc. This work is licensed under the Creative Commons Attribution International License (CC BY 4.0).

http://creativecommons.org/licenses/by/4.0/

\section{cc) (i) Open Access}

\begin{abstract}
Background: Numerous studies of tissues' regeneration have confessed the recovery of damaged liver by hematopoietic stem cells. The cells act not only by cell replacement in the target organ but also by delivering trophic factors that support endogenous liver regeneration. A little is known of how organ-derived signals recruit such committed cells into circulation. Objective: We investigated the roles of noninvasive mechanical percutaneous stress of cirrhotic human liver in numbers fluctuation of trophic, liver-specific alpha-fetoprotein-positive fraction of CD133-positive hematopoietic stem cells in lymphocytes of patients waiting for liver transplantation. Methods: To promote in blood the number of the alpha-fetoprotein-positive fraction of CD133-positive hematopoietic stem cells, committed to liver' tissue, we activated mechanically the cirrhotic liver of patient by transcutaneous micro vibration received from skin-contacted electro-magnetic vibraphones generated mechanical pulses with amplitude $10 \mu \mathrm{m}$ and smoothly changing frequency from $0.03 \mathrm{kHz}$ to $18 \mathrm{kHz}$ and back forth during one cycle duration 1 minute. The number of the alpha-fetoprotein-positive fraction of CD133-positive hematopoietic stem cells in lymphocytes of potential recipients was controlled by flow cytometry before and during daily sonication of skin area, which corresponds to liver projection on it. The 15 minutes cyclic sonication of the liver area performed daily for three weeks. Results: The sonication increased significantly averaged number of liver-specific alpha-fetoprotein-positive
\end{abstract}


CD133-positive blood lymphocytes in 2 - 3 times compared to a base lane. The second similar sonication, the same zone after three weeks break showed differences with baseline, but it was statistically insignificant. The result was specifically related to the liver as it showed the control sonication of the backbone's projection on the skin of a separate group of patients with cirrhotic liver from the waiting list. Conclusion: The stem cells committed to the liver recruit from the bone marrow into circulation, when organ mechanically stresses and secretes specific humoral signals to provoke of lymphopoiesis on host liver repair.

\section{Keywords}

Committed Stem Cells, Cirrhotic Liver, Waiting List, Mechanical Micro-Vibration, Regeneration

\section{Introduction}

The liver's capacity to undergo functional regeneration is mostly limited by acute mechanical injury, like partial hepatectomy or a single injection of toxic chemical substances, like carbon tetrachloride. The chronic/repeated or overwhelming injury often causes aberrant healing - the liver fibrosis that culminates in cirrhosis and hepatic failure. Both divergent processes are under control of a dynamic interplay between intrahepatic niche cells (parenchymal hepatocytes and non-parenchymal cells, including hepatic stellate cells, inflammatory cells, biliary epithelial cells, and liver sinusoidal endothelial cells) [1]. Along with intrahepatic cells, circulating hematopoietic stem/progenitor cells (HSC) derived from bone marrow (BM) can also contribute to liver regeneration by the fusion with damaged hepatocytes, or differentiation into hepatocyte-like cells, or exert a partial effect via their morphogenic and proangiogenic properties [2] [3] [4] [5]. Some agents modulated of hematopoiesis (granulocyte-colony stimulating factor: G-CSF, Plerixafor) use to mobilize HSCs into the bloodstream to reverse induced chronic liver injury, but they have standard limitations for administration to go ahead in terms of the number of cycles and the hematological toxicity [6]. Intraportal infusions of autologous HSCs from a preliminary aspirated bulk volume of $\mathrm{BM}(\approx 150 \mathrm{ml})$ represent another invasive approach to artificial enrichment of microenvironment of the cirrhotic liver by the HSCs trophogens [7].

Among different factors, the liver graft in cirrhotic patients can be the most natural long-term stimulus for recruitment into the peripheral blood of additional HSC [8], confirming the existence of a humoral information pathway (axis) between these two tissues. Earlier some data reported that among bulk HSCs population in the BM a small fraction of specifically liver-targeted cells preexists/resides and it may be mobilized into peripheral blood during stress and tissue injury, playing a precise role in the following reparation [9] [10] [11] [12]. Recently we showed that the orthotopic liver graft recruits the liver-specific (al- 
pha-fetoprotein-positive) afp $+\mathrm{CD} 133+\mathrm{HSC}$ and some endothelial angiogenic afp+ CD31+ cells into lymphocytes (Lph) fraction of the blood [13] [14]. It remains unknown how to subvert the expected stable pro-fibrotic paracrine signals in "BM-liver" axis of those needed in orthotopic liver transplantation (OLT) into a regenerative paracrine stimulus to promote specific recruitment of morphogenic HSC committed to the rest of liver parenchymal cells. Interestingly, HSCs generated during embryonic liver development had the ability to traffic between different tissues like HSCs from adults and they both were most likely highly regulated by humoral signals to guarantee that they reached their final destinations [15].

Having the positive experience of inducible recruitment of HSC into the blood by moderate transcutaneous mechanical micro vibration of sponges bones [16] [17], we hypothesized that the direct mechanical stress of cirrhotic liver tissues might change the stagnant pro-fibrotic paracrine signals in humoral "BM-liver" axis and thus open new opportunities to influence on the specific interplay between afp+-committed morphogenic HSC and target hepatocytes.

Aim of the study was to mobilize from BM into circulation the additional number of HSC committed to the liver via the humoral signals, which provoke in the organ by its transcutaneous mechanical micro-vibrations. Here, we demonstrate the distant recruitment of liver-committed HSCs into the bloodstream of patients needed the OLT by noninvasive transcutaneous mechanical vibration of the cirrhotic liver monitoring the circulating afp+ CD133+ HSCs and afp+ $\mathrm{CD} 31+$ angiogenic lymphocytes number. The study allows us to confirm the possibility of an indirect and non-invasive increase the number of trophic stem cells committed to the hepatic tissues of those who are in waiting for the life-saving transplantation of a donor's organ. The long waiting time is deadly for those patients, but it is not predictable very often, because transplants are achievable by chance. The new technic proposed by us is specific and has no limit in reapplication in contrast with traumatic and non-targeted method of auto-transplantation of HSC widely used now in clinic.

\section{Methods}

\subsection{Patients}

The nine subjects within the age range of 53 - 61 years with cirrhosis listed for liver transplantation according to Model for End-Stage Liver Disease (MELD-Na) range 6 - 15 were included in this study at the Russian Research Center of Radiology and Surgical Technologies in St. Petersburg, Russia. Cirrhosis was diagnosed by clinical symptoms, biochemical indexes of liver failure, and liver histologic findings or compatible imaging findings (e.g., ultrasonography, computed tomography, or elastography). Six of nine awaiting patients received courses of mechanical vibration through skin-contacted vibraphones on the liver projection area. Other three patients received vibrations of backbones a similar contact way. The samples of peripheral blood were taken at the different time 
elapsed since the start of sonication. The six healthy volunteers were involved in the investigation for the base level of blood parameters.

\subsection{Equipment}

The apparatus 'VITAFON-5 for vibroacoustic exposure was a serial certified source of electromechanical oscillations (GOST50444-92 and TU9444-009-23138557-2009 of RF). Standard vibraphones produced mechanical oscillations synchronously in the cyclic regime. The frequency of oscillations changed from 0.03 hertz $(\mathrm{Hz})$ to 18 kilohertz $(\mathrm{kHz})$ and back forth during $\approx 60$ seconds. The amplitude of oscillations kept unchangeable about $10 \mu \mathrm{m}$. Mechanical micro vibrations of 8 vibraphones with a diameter of $45 \mathrm{~mm}$ each own achieved liver tissues percutaneously. Unit of vibraphones consisted of two rows (four in each) with the distances between the centers of rows of $75 \mathrm{~mm}$ and the centers of vibraphones within each row of $55 \mathrm{~mm}$. Thus, the unit formed an active rectangular field of $12 \times 22 \mathrm{~cm}$, combined with a flat cloth frame with eight fixing sockets and adjustable soft fastenings for fixation on the human body.

\subsection{Procedure/Sonication}

The vibratory action usually performed once a day for 15 minutes sitting in a half/ lying position of patients. The block located on the right side of the patient so that the vibraphones tightly covers the projection region of the liver, and their lower eges coincide with the lower border of the ribs. Two main schemes of sonication of liver region were used. The scheme I of sonication included $15 \mathrm{mi}-$ nutes sonication daily, for 3 weeks (2d, 3d, and 4 th). Scheme II consisted of sonication 15 minutes daily during 3 weeks, then break 3 weeks, and repeated sonication ( $8^{\text {th }}-10$ th weeks). Scheme III served as a control for the scheme I and II. It consisted of mechanical micro vibrations from standard vibraphones with a smoothly varying frequency in the acoustic range $0.03-18 \mathrm{kHz}$ by successive cycles of 60 seconds duration, affecting simultaneously 8 pairs of points along the entire central line of the spine with a distance between vibraphones in each pair of $0.5 \mathrm{~cm}$ for 15 minutes daily during 3 weeks (2d and 4th) [18].

\subsection{Blood Samples}

Ten $\mathrm{ml}$ of peripheral blood was taken once from each of six healthy volunteers at the beginning of the investigation. At schemes I, II and III such samples were taken twice during a week before sonication. At scheme I, the three samples were taken during 4th-6th weeks after the start of sonication and 12 samples during the 10th-12th weeks. At scheme II, the 15 samples were taken during 4th-6th weeks after the start of sonication and 15 samples during the 10th-12th weeks. At referent scheme III the six samples were taken during 4th-6th weeks after the start of sonication of the region of backbones projection on spine.

\subsection{Preparation of Samples for Flow Cytometry}

At each follow-up visit, the blood of patients examined for signs of cell's immu- 
nophenotype. The goal was to identify specific features in cell parameters after sonication of liver area of a body in terms of percentages of circulating lymphocytes in synthetic phase $\mathrm{S}+$, cells $\mathrm{CD} 133+, \mathrm{CD} 31+$, double-positive cells afp+ $\mathrm{CD} 133+$, afp $+\mathrm{CD} 31+$, and derivate ratios (afp+ CD133+)/CD133+, (afp+ $\mathrm{CD} 31+) / \mathrm{CD} 31+$ and afp $+\mathrm{CD} 133+/ \mathrm{afp}+\mathrm{CD} 31+$. The mononuclear cell fraction (MNC) isolated by classical Ficoll density separation immediately after the collection of peripheral blood $(10 \mathrm{~mL})$, omitting the final step of magnetic cell enrichment. [19]. Viability assessed using the trypan blue exclusion test. Cells from two equal portions of the fresh MNC fraction stained for flow cytometry analysis. The nucleic acid stained by Hoechst 33342 (bis-benzimidazole fluorochrome; Sigma-Aldrich, St. Louis, MO, USA) for cell cycle analysis, which performed as described previously [20], with slight modifications. First MNCs resuspended at a density of $1067 / \mathrm{mL}$ in pre-warmed $\left(37^{\circ} \mathrm{C}\right)$ Dulbecco's Modified Eagle's Medium supplemented with 2\% heat-inactivated fetal calf serum (Gibco BRL, Grand Island, NY, USA) and 10 mM HEPES (Gibco BRL). Then Hoechst 33342 added to a final concentration of $5 \mu \mathrm{g} / \mathrm{mL}$, and the cells placed in a water bath at $37^{\circ} \mathrm{C}$ for 120 minutes. Tubes mixed gently every 20 minutes during incubation. The cells were then centrifuged (483 relative centrifugal force for $6 \mathrm{mi}-$ nutes at $4^{\circ} \mathrm{C}$ in a precooled rotor), resuspended in cold Hank's Balanced Salt Solution/2\% fetal calf serum/10 mM 4-(2-hydroxyethyl)-1-piperazineethanesulfonic acid (HEPES) at a concentration of $1-2 \times 10^{7} / \mathrm{mL}$, and kept at $4^{\circ} \mathrm{C}$ until analysis.

The phenotypes of the circulating cells in the lymphoid part of the mononuclear cells (MNC) were evaluated using standard protocols for cell staining. MNCs prepared for conventional dual-color immunophenotyping with the fluorescence of allophycocyanin (APC)-directly conjugated anti-CD133/2 monoclonal antibodies (MoAbs), fluorescein isothiocyanate (FITC) directly conjugated anti-CD31 MoAbs, and phycoerythrin (PE)-directly conjugated anti-AFP ( $\alpha$-fetoprotein) MoAbs. The APC-conjugated MoAbs were from Miltenyi Biotech (Bergisch Gladbach, Germany), the FITC-conjugated MoAbs were from BD Bioscience Pharmingen (San Jose, CA, USA), and the PE-conjugated MoAbs were from R\&D Systems (Minneapolis, MN, USA). Isotype-matched irrelevant MoAbs (Becton-Dickinson) used as negative controls.

\subsection{Flow Cytometry}

An LSR Fortessa flow cytometer (Becton-Dickinson, San Jose, CA, USA) adjusted for immunofluorescence before each measurement using the BD Cytometer Setup and Tracking Beads kits. The Lph and monocytes (Mn) fractions were separated by gating on forward (FSC) and side (SSC) light scatter dot plots, excluding cellular debris. A red laser $(640 \mathrm{~nm}, 40 \mathrm{~mW})$ used for the detection of CD133+ cells, a blue laser ( $480 \mathrm{~nm}, 50 \mathrm{~mW}$ ) used for detection of AFP+ and $\mathrm{CD} 31+$ cells, and an ultraviolet (UV) laser $(355 \mathrm{~nm}, 20 \mathrm{~mW})$ for cells labeled with Hoechst 33342. 


\subsection{Flow Cytometry Analysis}

All dates related to lymphocyte fraction of MNC. A minimum of 500,000 total events recorded twice for CD133+ cells detection. The percentage of positive cells calculated by subtracting the value of the appropriate isotype control. A dot plot of double (simultaneous) emission of Hoechst 33342 in blue (x-axis) and red (y-axis) wavelengths used for separation of events $(\mathrm{G} 0+\mathrm{G} 1), \mathrm{S}$, and $(\mathrm{G} 2+$ $\mathrm{M})$ phases, as previously described. The major double (blue and red)-negative emitting population in the lower left corner of the plot represents cells in the (G0 + G1) phases of the cell cycle. The population located in the center and upper right corner of the dot plot represent the double emitting cells in the S-phase and mitotic phase (Mt) of the cell cycle respectively [19] [20].

\subsection{Statistical Analyses}

Single parameters were evaluated statistically with the calculation of an average (M), standard deviation (SD) and standard error (SE). The average values $M$ were compared using $\mathrm{t}$-criterion and probability $\mathrm{p}$. We described the trends of the aggregate parameters before and after sonication by mathematical functions generated automatically using non-linear approximations in the Excel program. The coefficient determination $R^{2}$ used as a statistical measure of the goodness of fit of the regression line to the data. Satisfactory $R^{2}$ values were confirmed using Equation (1) for $t$-parameter [21]:

$$
t=\sqrt{R^{2}} \times(n-2) /\left(1-R^{2}\right)
$$

\section{Results}

The data of Table 1. characterize the content of CD133-positive and CD31-positive populations in peripheral lymphocytes and their $\alpha$-fetoprotein-positive (afp+) derivates (subpopulations) for volunteers.

Figure 1 shows the relative deviation of signs for patients with liver cirrhosis to corresponded signs for healthy volunteers in Table 1.

Relative decreasing of S+, CD31+ cells and a slight increase of CD133+ cells are typical for patients awaiting liver transplantation.

Figure 2 summarizes early results of sonication of the liver area according to the scheme I and II at fourth-fifth week after the start of treatment.

Table 1. Base parameters (BP) of circulating lymphocytes for healthy volunteers, percentage.

\begin{tabular}{ccccccccccc}
\hline BP & $\mathrm{CD} 133+$ & $\begin{array}{c}\mathrm{CD} 133+ \\
\mathrm{afp}+\end{array}$ & $\mathrm{CD} 31+$ & $\begin{array}{c}\mathrm{CD} 31+ \\
\mathrm{afp}+\end{array}$ & $\mathrm{s}$ & $\begin{array}{c}\mathrm{CD} 133+/ \\
\mathrm{CD} 31+\end{array}$ & $\begin{array}{c}\mathrm{CD} 133+\mathrm{afp}+/ \\
\mathrm{CD} 31+\mathrm{afp}+\end{array}$ & $\begin{array}{c}\mathrm{CD} 133+\mathrm{afp}+/ \\
\mathrm{CD} 133+\end{array}$ & $\begin{array}{c}\mathrm{CD} 31+\mathrm{afp}+\text { / } \\
\mathrm{CD} 31+\end{array}$ \\
\hline $\mathrm{M}$ & 0.037 & 0.0052 & 40.1 & 0.39 & 0.95 & $0.101^{*}$ & $1.64^{*}$ & $12.36^{\star}$ & $0.97^{\star}$ \\
$\mathrm{SD}$ & 0.012 & 0.0044 & 9.2 & 0.36 & 0.98 & 0.037 & 1.25 & 8.22 & 0.74 \\
$\mathrm{SE}$ & 0.004 & 0.0015 & 3.1 & 0.12 & 0.28 & 0.013 & 0.44 & 2.90 & 0.24 \\
$\mathrm{KV}$ & 0.32 & 0.84 & 0.23 & 0,92 & 1.03 & 0.37 & 0.76 & 0.66 & 0.76 \\
\hline
\end{tabular}

*Obtained by averaging the personal ratios. 


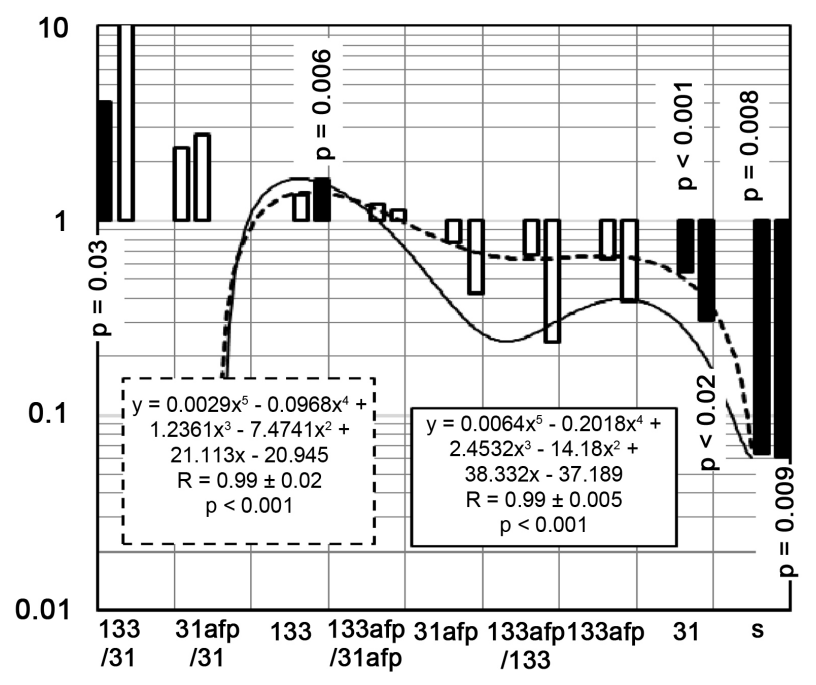

Figure 1. Relative changes of averaged cell parameters $(M)$ at cirrhosis to those for healthy volunteers accepted as 1.0. Right columns correspond to data received before treatment according to the scheme I (solid line). Left columns correspond to data received before treatment according to scheme II and scheme III (dashed line). Statistically valid deviations are black.

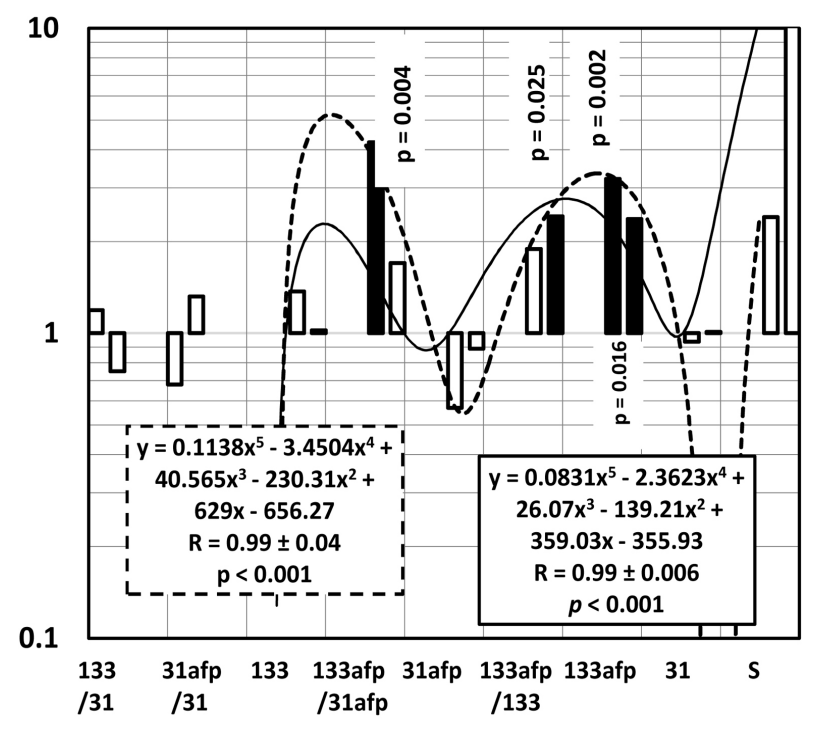

Figure 2. Relative changes of averaged cell parameters (M) after a fourth-fifth week of sonication of the liver area to those for untreated patients in Figure 1 accepted as 1.0. The right and left columns show the relative data received at 4 th-6th weeks after the start of sonication according to the scheme I (solid line, right columns) and scheme II (dashed line, left columns) respectively.

The sonication normalized the preexisted abnormalities of $\mathrm{S}+, \mathrm{CD} 31+$ and $\mathrm{CD} 133+$ cells before treatment shown in Figure 1. Moreover, it increases the number of double positive CD133+ afp+ cells, which are committed to liver tis- 
sue.

The increasing of CD133+ afp+ cells in Figure 2 is specific for sonication of the liver area because the use of referent scheme III at spine area resulted in significant increasing only CD133+ population (Figure 3).

The sonication of backbones significantly increases the number of non-committed CD133+ cells in circulation not only over their number before spine treatment (Figure 3 ) but over the number of CD133+ cells after the first course of liver sonication, shown in Figure 2. as relative units. The real concentrations corresponded to Figure 2. Are $0.07 \pm 0.022 \pm 0.0125$ (the scheme I) and $0.079 \pm 0.037 \pm 0.0099$ (Scheme II). These mean values increase by backbones sonication (scheme III) 1.95 fold $(\mathrm{p}=0.006)$ and 1.75 fold $(\mathrm{p}=0.008)$ correspondently.

There is no any specific changes registered at 10th-12th weeks after a single course of sonication according to the scheme I as it is seen in Figure 4 (right columns with solid line).

After double courses of liver area sonication according to Scheme II, all preexisted specific rise of CD133+ afp+ cells disappear at 10th-12th weeks, but they substitute by non-specific increasing of CD133+ cells. The S+ cells became elevated also compared to the corresponding data before the start of sonication shown in Figure 1 (dashed line, left columns).

Thus, the phenomenon of indirect transcutaneous mechanical mobilization of CD133+ afp + hematopoietic stem cells committed to the targeted liver tissues arises during $4-6$ weeks of sonication and disappears to $10^{\text {th }}-12^{\text {th }}$ weeks. There was no chance to reproduce the peak of CD133+ afp + by repeated sonication during the 8 th-10th weeks at least.

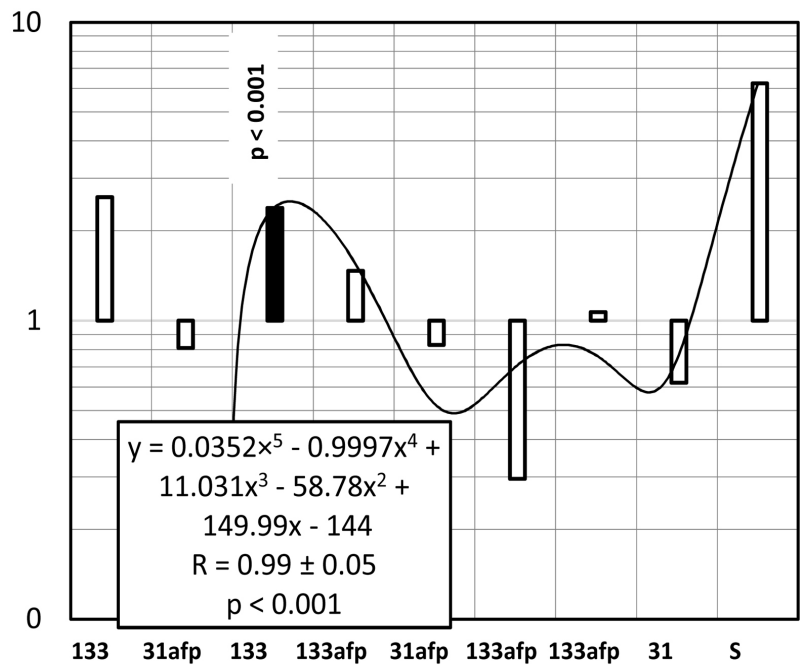

Figure 3. Relative changes of averaged cell parameters (M) after the start of sonication of the spine area to those for untreated patients in Figure 1 accepted as 1.0. The columns show the relative data received at 4 th-6th weeks after the start of sonication according to Scheme III. 


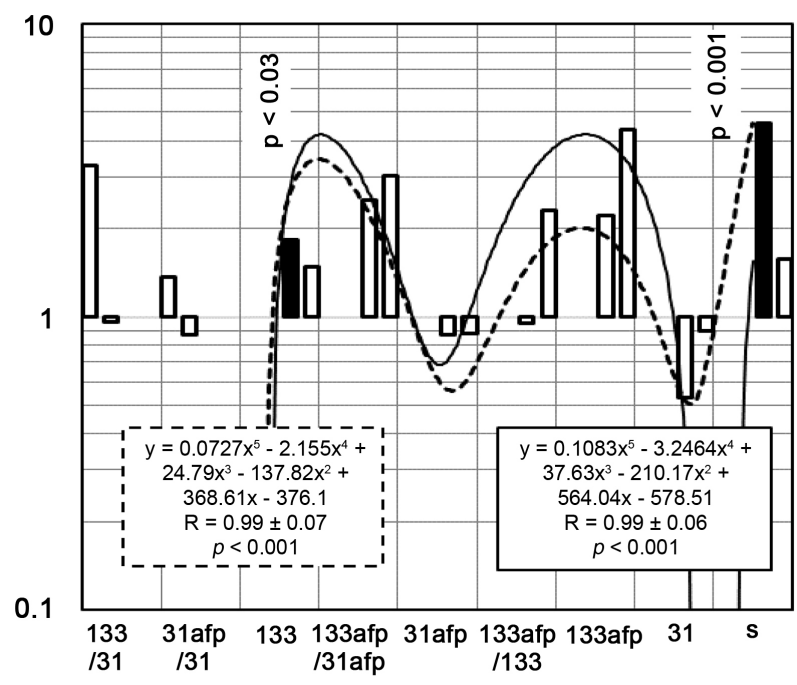

Figure 4. The relative changes of averaged cell parameters (M) during the tenth-fifteenth weeks after the start of sonication of the liver area to those for untreated patients in Figure 1. The columns show the relative data received at 10th-12th weeks after the start of sonication according to the scheme I (solid line, right columns) and scheme II (dashed line, left columns) respectively.

\section{Discussion}

It is clear that physical factors play very critical roles in biological processes. The applications of tensile strain, shear stress, electromagnetic fields, and ultrasound are among many options to enhance osteogenesis and chondrogenesis of human stem cell. Therefore, direct physical intervention is an appealing approach and should be profoundly exploited to improve clinical outcomes in tissues regeneration

There is no today medical approach for support of patients with cirrhotic liver on long and non-invasive base, apart from the prediction of optimal waiting time for liver transplantation [22]. The goal of the present article was an evaluation of the influence of the micro-vibrations on the interaction between bone marrow and liver at the level of inter-organs relation [2]. We expect that humoral signal of unknown nature from artificially stressed liver's tissues achieve the BM lymphopoietic niches and intensify either the natural production of liver committed morphogenic CD133+ afp+ lymphocytes, or their recruitment into circulations, which both suppress originally by disease. If it were true, we would receive a new approach for non-invasive and long-term targeted support of a liver function of patients waiting for a suitable transplant from a compatible donor.

Some authors found that liver exhibits mechanical resonance within registered frequencies $30-400 \mathrm{~Hz}$, depending on odd harmonics 1 - 3 [23]. The liver itself has a frequency of around $55-60 \mathrm{MHz}$. The liver has also its own frequency around $55-60 \mathrm{MHz}$ [24]. To non-invasive influence on that little-known com- 
plex system, the mechanical vibrations seemed promising, as they may produce Stochastic Resonance (SR) in nonlinear biological systems, which enhance the performance of subthreshold stimuli in metabolic pathways [25] [26]. To increase the probability of the resonance process in liver tissues, we have chosen a unique source of mechanical vibrations in a wide range of frequencies [18]. The several reasons took into account in this study for using circulating lymphocytes as objects. First, lymphoid cells have most developed and flexible mechanisms of navigation toward different tissues/tropic/ and contain fractions of morphogenic/trophic cells such like CD133+, CD34+ HSC, lymphoid TdT+ cells, angiogenic CD31+ cells and other trophic unmatured cells, which usually termed as regulatory cells. Secondly, the lymphocytopoiesis is a most damaged process, and lymphoid tissue exhibits the highest loss of actual and functional mass during the life [27]. Third, the high neutrophil-to-lymphocyte ratio (NLR) is associated with a worse prognosis in various diseases of organs, including the liver [28].

In the blood of patients, we registered the deficit of naive CD31+ lymphocytes with angiogenic properties [29] [30] as well, like lymphocytes, being in the S-phase of DNA synthesis. The first course of liver or spine sonication both normalized both mentioned deficits (Figure 2 and Figure 3). Thus, it is an argument against the specificity of these two effects.

On the contrary, first sonication of the liver increases of CD133+ afp+ cells, that seems quite committed (specific) to the liver tissues (Figure 2 and Figure $3)$. We interpret the arising CD133+ afp+ cells number, as a remote result of specific paracrine stimulus originated from mechanically stressed liver parenchyma. The humoral stimulus aimed at the reproductive system of bone marrow activate and specifically recruit trophic/morphogenic marrow stem cells committed to recovering the damaged liver [31]. The signals could be either easily solved molecular substances in plasma or circulating extracellular vesicles with a size of tenths micron, recently discovered [32]. In this instance, the mechanical vibrations mimic the real damage of the liver.

Several cells of the liver might be as a target for interaction with committed CD133+ afp+ cells. Among liver, parenchymal cells is a population of CD133+ oval cells with the function of primitive, bipotent liver stem cells [33] [34], but they do not include AFP marker [35]. That is why the youngest resident hepatic stem cells (HepSCs) are hardly a target for afp $+\mathrm{CD} 31+$ lymphocytes. Immature unipotent hepatoblasts, which expand during regenerative processes in the liver, have an antigenic profile, with strongly positive expression of both CD133 and the hepatic-specific AFP-marker [36] [37]. Thus, they are likely to be a target for CD133+ afp+-committed migrants [13].

Neither HepSCs nor immature unipotent hepatoblasts have at least one of the two markers AFP or CD31. [36], and we do not register any statistical proves of afp + CD31+ lymphocytes response on the liver' sonication (Figure 2 and Figure 4). This coincidence may be an additional argument for the hepatoblasts are most probable impact targets for humoral stimulus induced by liver mechanical 
sonication.

Remarkable, that in terms of CD133+ afp+-committed migrants the second course of the liver area exposure (scheme II) did not change the effect of the first course. The reasons for that do not clear completely, but a limitation of lymphocytopoiesis in cirrhotic patients (Figure 1) and related instability/turbulence of it [13] [14] may be one of the possible causes. On the other hand, an exhausted/amortized natural ability of cirrhotic parenchyma to produce paracrine replay to mechanical stress might be the reason for that.

\section{Conclusion}

In conclusion, these results provide only a therapeutic roadmap to achieve long term non-invasive support of hepatic function without a traumatic transfusion of auto HSC or drugs stimulation of those awaiting the liver transplantation. Additional clinical investigations with the MELD/Na Score and the Child-Pugh Score [38] need for creating an effective and stable algorithm of employment found phenomenon.

\section{Acknowledgements}

This work was supported by the Ministry of Health in accordance with the open scientific plan of the center without any reservations regarding the open publication of the expected results.

\section{Conflicts of Interest}

The authors declare that they have no conflicts of interest.

\section{References}

[1] Ding, B.-S., Cao, Z., Lis, R., Nolan, D.J., Guo, P., Simons, M., et al. (2014) Divergent Angiocrine Signals from Vascular Niche Balance Liver Regeneration and Fibrosis. Nature, 505, 97-102. https://doi.org/10.1038/nature12681

[2] Woo, D.H., Kim, S.K., Lim, H.J., Heo, J., Park, H.S., Kang, G.Y., et al. (2012) Direct and Indirect Contribution of Human Embryonic Stem Cell-Derived Hepatocyte-Like Cells to Liver Repair in Mice. Gastroenterology, 142, 602-611. https://doi.org/10.1053/j.gastro.2011.11.030

[3] Ratajczak, J., Kucia, M., Mierzejewska, K., Marlicz, W., Pietrzkowski, Z., Wojakowski, W., et al. (2013) Paracrine Proangiopoietic Effects of Human Umbilical Cord Blood-Derived Purified CD133+ Cells-Implications for Stem Cell Therapies in Regenerative Medicine. Stem Cells and Development, 22, 422-430. https://doi.org/10.1089/scd.2012.0268

[4] Liu, W.-H., Ren, L.-N., Wang, T., Navarro-Alvarez, N. and Tang, L.-J. (2016) The Involving Roles of Intrahepatic and Extrahepatic Stem/Progenitor Cells (SPCs) to Liver Regeneration. International Journal of Biological Sciences, 12, 954-963. https://doi.org/10.7150/ijbs.15715

[5] Abdellatif, H. and Shiha, G. (2018) PD-L1 Expression on Circulating CD34+ Hematopoietic Stem Cells Closely Correlated with T-Cell Apoptosis in Chronic Hepatitis C Infected Patients. International Journal of Stem Cells, 11, 78-86. 
https://doi.org/10.15283/ijsc17047

[6] Tsolaki, E., Athanasiou, E., Gounari, E., Zogas, N., Siotou, E., Yiangou, M., et al. (2014) Hematopoietic Stem Cells and Liver Regeneration: Differentially Acting Hematopoietic Stem Cell Mobilization Agents Reverse Induced Chronic Liver Injury. Blood Cells, Molecules, and Diseases, 53, 124-132. https://doi.org/10.1016/j.bcmd.2014.05.003

[7] Mohamadnejad, M., Vosough, M., Moossavi, S., Nikfam, S., Mardpour, S., Akhlaghpoor, S., et al. (2016) Intraportal Infusion of Bone Marrow Mononuclear or CD133+ Cells in Patients with Decompensated Cirrhosis: A Double-Blind Randomized Controlled Trial. Stem Cells Translational Medicine, 5, 87-94. https://doi.org/10.5966/sctm.2015-0004

[8] Lemoli, R.M., Catani, L., Talarico, S., Loggi, E., Gramenzi, A., Baccarani, U., et al. (2007) Mobilization of Bone Marrow-Derived Hematopoietic and Endothelial Stem Cells after Orthotopic Liver Transplantation and Liver Resection. Stem Cells, 24, 2817-2825. https://doi.org/10.1634/stemcells.2006-0333

[9] Kucia, M., Ratajczak, J., Reca, R., Janowska-Wieczorek, A. and Ratajczak, M.Z. (2004) Tissue-Specific Muscle, Neural and Liver Stem/Progenitor Cells Reside in the Bone Marrow, Respond to an SDF-1 Gradient and Are Mobilized into Peripheral Blood during Stress and Tissue Injury. Blood Cells, Molecules and Diseases, 32, 52-57. https://doi.org/10.1016/j.bcmd.2003.09.025

[10] Ratajczak, M.Z., Kucia, M., Reca, R. and Majka, M. (2004) Stem Cell Plasticity Revisited: CXCR4-Positive Cells Expressing mRNA for Early Muscle, Liver and Neural Cells "Hide Out" in the Bone Marrow. Leukemia, 18, 29-40. https://doi.org/10.1038/sj.leu.2403184

[11] Kucia, M., Ratajczak, J. and Ratajczak, M.Z. (2005) Bone Marrow as Source of Circulating CXCR4+ Tissue Committed Stem Cells. Biology of the Cell, 97, 133-146. https://doi.org/10.1042/BC20040069

[12] Kucia, M., Reca, R., Jala, V.R., Dawn, B., Ratajczak, J. and Ratajczak, M.Z. (2005) Bone Marrow as a Home a Heterogenous Populations of Nonhematopoietic Stem Cells. Leukemia, 19, 1118-1127. https://doi.org/10.1038/sj.leu.2403796

[13] Shoutko, A.N., Gerasimova, O.A., Ekimova, L.P., Zherebtsov, F.K., Mus, V.F., Granov, D.A., et al (2016) Long-Term Activation of Circulating Liver-Committed Mononuclear Cells after OLT. Jacobs Journal of Regenerative Medicine, 1, Article ID: 011.

https://jacobspublishers.com/long-term-activation-of-circulating-liver-committedm on

[14] Shoutko, A.N., Gerasimova, O.A., Ekimova, L.P., Zherebtsov, F.K., Mus, V.F., Matyurin, K.S., et al. (2017) Lymphocyte Reproductive Activity Normalized to Numbers of Hematopoietic Stem Cells in Blood and Rate of Death in Fatal Diseases. International Journal of Genetics and Genomics, 5, 54-62.

https://doi.org/10.11648/j.ijgg.20170505.12 http://www.sciencepublishinggroup.com/j/ijgg

[15] Heinig, K., Sage, F., Robin, C. and Sperandio, M. (2015) Development and Trafficking Function of Hematopoietic Stem Cells and Myeloid Cells during Fetal Ontogeny. Cardiovascular Research, 107, 352-363. https://doi.org/10.1093/cvr/cvv146

[16] Karamullin, M., Baback, A., Ekimova, L., Phedorov, V., Kireeva, E., Sosukin, A., et al. (2008) The Blood Stem Cell's Pool Modulation in Remote Period Improved Health Status of Chernobyl Clean-Up Workers. Radioprotection, 43, 89. https://doi.org/10.1051/radiopro:2008667 
[17] Baback, A., Karamullin, M., Ekimova, L., Phedorov, V., Kireeva, E., Sosukin, A., et al. (2008) Exercise Performance vs. Growth of Haemopoietic Stem Cells Amount in CUWs Blood after Nonivasive Modulation. Radioprotection, 43, 161. https://doi.org/10.1051/radiopro:2008724

[18] Shutko, A.N. and Fedorov, V.A. (2008) Sposob Obogascheniya Krovi Stvolovimi Krovetvornimi Kletkami. Patent Rossiiskoi Federacii \#2166924, klass A61H23/00, BI:20/200; epab 20.07/2008. (In Russian). Http://ru-patent.info/21/65-69/2166924.html

[19] Eaker, Sh.S., Hawley, T.S., Ramezani, A. and Hawley, R.G. (2004) Detection and Enrichment of Hematopoietic Stem Cells by Side Population Phenotype. In: Hawley, T.S. and Hawley, R.G., Eds., Methods Inmolecular Biology: Flow Cytometry Protocols, 2nd Edition, Humana Press Inc., Totowa, 161-180. https://doi.org/10.1385/1-59259-773-4:161 https://flowcytometry.gwu.edu/.../flowcytometry.../fcp9.pdf

[20] Sales-Pardo, I., Avendaño, A., Martinez-Muñoz, V., García-Escarp, M., Celis, R., Whittle, P., et al. (2006) Flow Cytometry of the Side Population: Tips and Tricks. Cellular Oncology, 28, 37-53. https://www.ncbi.nlm.nih.gov/pubmed/16675880

[21] Loveland, J.L. (2013) Mathematical Justification of Introductory Hypothesis Tests and Development of Reference Materials. All Graduate Plan B and Other Reports. Utah State University, Logan, 14. https://digitalcommons.usu.edu/gradreports/14

[22] Trieu, J.A., Bilal, M. and Hmoud, B. (2018) Factors Associated with Waiting Time on the Liver Transplant List: An Analysis of the United Network for Organ Sharing (UNOS) Database. Annals of Gastroenterology, 31, 84-89. https://doi.org/10.20524/aog.2017.0217

[23] Oldenburg, A.L. and Boppart, S.A. (2010) Resonant Acoustic Spectroscopy of Soft Tissues Using Embedded Magnetomotive Nanotransducers and Optical Coherence Tomography. Physics in Medicine \& Biology, 55, 1189-1201. https://doi.org/10.1088/0031-9155/55/4/019

[24] Sharma, A. and Maurya, A.K. (2017) Aggregate Frequencies of Body Organs. International Journal of Electrical, Electronics and Data Communication, 5, 94-98. http://iraj.in

[25] Arredondo, L.T. and Perez, C.A. (2017) Spatially Coincident Vibrotactile Noise Improves Subthreshold Stimulus Detection. PLOS ONE, 12, e0186932. https://doi.org/10.1371/journal.pone.0186932

[26] Milanese, C., Cavedon, V., Sandri, M., Tam, E., Piscitelli, F., Boschi, et al. (2018) Metabolic Effect of Bodyweight Whole-Body Vibration in a 20-min Exercise Session: A Crossover Study Using Verified Vibration Stimulus. PLoS ONE, 13, e0192046. https://doi.org/10.1371/journal.pone.0192046

[27] Richardson, R.B., Allan, D.S. and Lea, Y. (2014) Greater Organ Involution in Highly Proliferative Tissues Associated with the Early Onset and Acceleration of Ageing in Humans. Experimental Gerontology, 55, 80-91. https://doi.org/10.1016/j.exger.2014.03.015

[28] Agiasotelli, D., Alexopoulou, A., Vasilieva, L., Kalpakou, G., Papadaki, S. and Dourakis, S.P. (2016) Evaluation of Neutrophil/Leukocyte Ratio and Organ Failure Score as Predictors of Reversibility and Survival Following an Acute-On-Chronic Liver Failure Event. Hepatology Research, 46, 514-520. https://doi.org/10.1111/hepr.12582

[29] Ashman, L.K. and Aylett, G.W. (1991) Expression of CD31 Epitopes on Human Lymphocytes: CD31 Monoclonal Antibodies Differentiate between Naive 
(CD45RA+) and Memory (CD45RA-) CD4-Positive T Cells. Tissue Antigens, 38, 208-212. https://doi.org/10.1111/j.1399-0039.1991.tb01899.x

[30] Hur, J., Yang, H.-M., Yoon, Ch.-H., Lee, Ch.-S., Park, K.-W., Kim, J.-H., et al. (2007) Identification of a Novel Role of T Cells in Postnatal Vasculogenesis. Characterization of Endothelial Progenitor Cell Colonies. Circulation, 116, 1671-1682. https://doi.org/10.1161/CIRCULATIONAHA.107.694778

[31] Huch, M. and Dolle, L. (2016) The Plastic Cellular States of Liver Cells: Are EpCAM and Lgr5 Fit for Purpose? Hepatology, 64, 652-662. https://doi.org/10.1002/hep.28469

[32] Teixeira, J.H., Silva, A.M., Almeida, M.I., Barbosa, M.A. and Santos, S.G. (2016) Circulating Extracellular Vesicles: Their Role in Tissue Repair and Regeneration. Transfusion and Apheresis Science, 55, 53-61. https://doi.org/10.1016/j.transci.2016.07.015

[33] Rountree, C.B., Barsky, L., Ge, S.H., Zhu, J., Senadheera, S.H. and Crooks, G.M. (2007) A CD133-Expressing Murine Liver Oval Cell Population with Bilineage Potential. Stem Cells, 25, 2419-2429. https://doi.org/10.1634/stemcells.2007-0176

[34] Corbeila, D., Fargeasa, C.A. and Jászaib, J. (2014) CD133 Might Be a Pan Marker of Epithelial Cells with Dedifferentiation Capacity. PNAS, 111, E1451-E1452. https://doi.org/10.1073/pnas.1400195111

[35] Turner, R., Lozoya, O., Wang, Y., Cardinale, V., Gaudio, E., Alpini, G., et al. (2011) Human Hepatic Stem Cell and Maturation Liver Lineage Biology. Hepatology, 53, 1035-1045. https://doi.org/10.1002/hep.24157

[36] Haruna, Y., Saito, K., Spaulding, S., Nalesnik, M.A. and Gerber, M.A. (1996) Identification of Bipotential Progenitor Cells in Human Liver Development. Hepatology, 23, 476-481. https://doi.org/10.1002/hep.510230312

[37] Liang, O.D., Korff, T., Eckhardt, J., Rifaat, J., Baal, N., Herr, F.T., et al. (2004) Oncodevelopmental Alphafetoprotein Acts as a Selective Proangiogenic Factor on Endothelial Cell From the Fetomaternal Unit. The Journal of Clinical Endocrinology \& Metabolism, 89, 1415-1422. https://doi.org/10.1210/jc.2003-031721

[38] Puentes, J.C.P., Rocha, H., Nicolau, S. and Ferrão, G. (2018) Effectiveness of the MELD/Na Score and the Child-Pugh Score for the Identification of Palliative Care Needs in Patients with Cirrhosis of the Liver. Indian Journal of Palliative Care, 24, 526-528. https://www.ncbi.nlm.nih.gov/pubmed/30410269 https://doi.org/10.4103/IJPC.IJPC_97_18 